(2) Rate and degree of metabolism in the liver;

(3) Variations in the percentage binding to serum (although from rather limited data it would seem that this plays a minor contribution).

(4) Rate of diffusion into the tissues.

If one is considering an oral penicillin there are two additional factors:-

(5) Rate of absorbtion from the intestine;

(6) Rate of inactivation in the intestine.

A large volume of data on variations in serum penicillin levels has been obtained from work carried out with depot preparations of procaine benzyl penicillin in oil (to be published). Figure 1 shows frequency histograms of blood levels obtained in humans 24 hours after a single fixed dose of the same prepara-D tion. Large groups of individuals were involved and there was an interesting difference between Clinic $\mathrm{C}$ and the other two clinics? With a preparation of this type there is the added variable of the rate of release of penicillin from the oil depot into the blood stream.

In choosing the dose of a penicillin fores therapy presumably it should be one which isadequate even for individuals with the lowest serum levels found in this type of distribution $\vec{\omega}$ Usually only mean blood levels are quoted and no idea is given of the range found in normal population, and no comparison appears to have been made of the ranges of thes various penicillins. A penicillin producinges a small range of blood levels at any giveño time would be advantageous.

\title{
THE SIGNIFICANCE OF PROTEIN BINDING OF PENICILLINS
}

\author{
G. N. Rolinson \\ Beecham Research Laboratories, Brentford, Middlesex
}

IT is quite well known that many drugs, including antibiotics, are reversibly bound by proteins in the serum, and also by proteins in the issues, with the result that in vivo the drug exists partly in the form of a protein-bound complex and partly as the free compound. This is illustrated in Figure 1.

\section{PROTEIN + FREE $\rightarrow$ PROTEIN-BOUND ANTIBIOTIC $\rightleftharpoons \quad$ ANTIBIOTIC}

Figure 1.

Since the binding to the protein is reversible an equilibrium exists between protein and free antibiotic on the one hand, and protein-bound drug on the other. If this equilibrium is disturbed, for example if free drug is removed or if the concentration of protein is diminished, the protein-bound complex breaks down to liberate free drug to maintain the equilibrium or to establish a new one. Results of experiments in our own laboratory indicate that the binding of antibiotics to serum proteins takes place extremely rapidly and that the breakdown of the protein-bound complex also occurs equally quickly.

In the system shown in Figure 1 the point of equilibrium, that is to say the proportion of drug bound relative to the proportion free, depends on a number of factors of which the most important are the particular drug in:question and the particular protein in question 3 In the case of penicillins, binding in the serum takes place almost entirely with the albumin fraction. However, although our owno experiments do not indicate any significant difference in extent of binding between serao of different human subjects there is extensive information illustrating the difference in degree $\mathrm{N}$ of binding between sera of different animal N species. An example of this is shown in N Table I. It will be seen that with oxacilling in dog serum about one-third is present as free drug whereas in human serum only $6.9 \%$ is unbound. Differences also occur in the relative binding for two different antibiotics. For example, oxacillin and penicillin $\mathrm{V}$ are $\overline{0}$ 


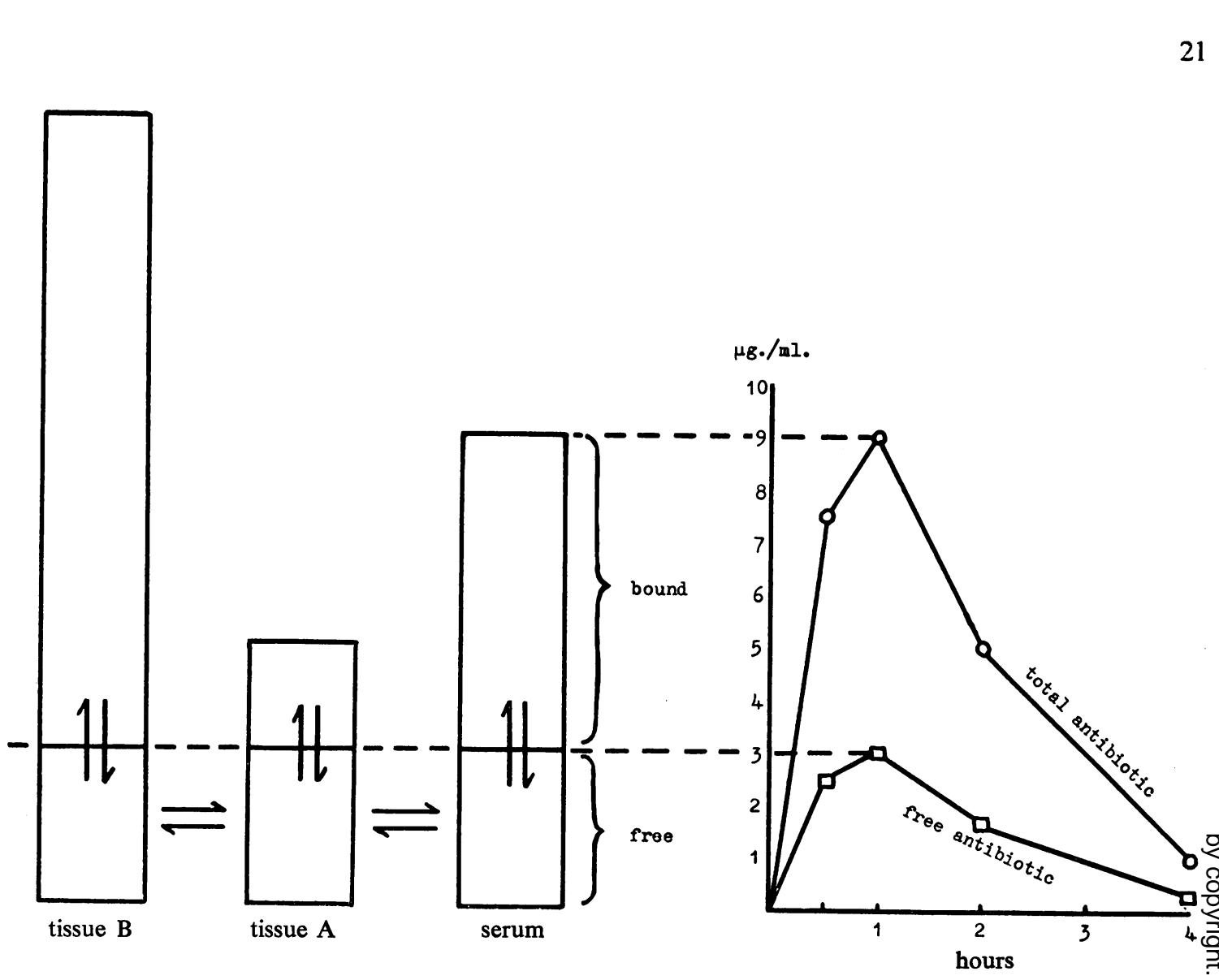

FIG. 2.-The effect of protein binding of an antibiotic on its subsequent distribution in the tissues.

bound to a similar extent in the dog but to very different extents in the human.

The significance of the particular drug in relation to the extent of binding is also shown in Table 1. In human serum the percentage of free, unbound drug can be as high as 82 per cent with ampicillin or as low as 0.8 per cent with novobiocin.

Protein-bound antibiotic exhibits two important properties.

Firstly, the protein-bound drug has little or no antibacterial activity and there is considerable evidence to support this contention. Secondly, in addition to being virtually inactive the protein-bound antibiotic is also relatively non-diffusible. The primary effect of binding in the serum therefore is to confine the drug within the vascular system in an inactive form. This is illustrated in Figure 2. Serum concentrations are shown for a hypothetical antibiotic for which two-thirds of the drug is bound in the serum and one-third is free and at the time of peak serum levels these propor-
TABLE I.

antibiotic in serum
Antibiotic
human


equilibrium between bound and free antibiotic will exist in a similar way to that in the serum. It will be appreciated that for a given tissue the proportion of bound drug relative to free drug may be very different from that in the serum. We have already seen that the equilibrium between bound and free drug depends on the concentration and the nature of the protein present. If the protein concentration of the tissue fluid is low the proportion of the drug in the bound form will also be low. This is again illustrated by reference to Figure 2. In this diagram, tissue A represents a fluid in which the protein concentration is low while in tissue $B$ the protein concentration is high. It will be seen, therefore, that the total concentration of antibiotic in a given tissue may be higher, or lower, than that in the serum. Notwithstanding this, at equilibrium, the concentrations of unbound drug in the tissues and in the serum will be the same.

The significance of serum binding therefore is that it determines the level of unbound drug in the serum which in turn determines the level of unbound (and active) drug in the tissues. If diffusion of the unbound drug is slow the concentration of free antibiotic in the tissues may well be lower than that in the serum but it cannot be any higher than the peak level of unbound drug reached in the serum since this is the maximum concentration gradient for diffusion.

In certain parts of the body special problems of diffusion exist. For example, certain antibiotics do not pass the blood-brain barrier at all readily regardless of whether they are protein-bound or not. On the other hand, with drugs which do pass into the C.S.F. readily it is only the unbound fraction which is free to diffuse across.

As the serum levels of antibiotic fall the process of diffusion is reversed; the proteinbound depots of antibiotic in the tissues break down as the unbound drug diffuses back into the vascular system, then to be eliminated from the body by various means. If the route of excretion is primarily by glomerular filtra- $\frac{3}{0}$ tion, with negligible secretion, the rate of $\frac{\varrho}{c}$ elimination from the body is diminished as the extent of binding increases. On the other hand, if there is extensive tubular secretion, oro secretion in the bile, since these processes are을 not proportional to the concentration of free⿳亠丷厂 drug, the extent of binding has little influence $\stackrel{\Phi}{\propto}$ on the rate of elimination from the body.

The point is sometimes made that proteinbound antibiotic can leave the vascular system, particularly when there is inflammation and $\vec{\omega}$ that this complex may break down in theo tissue fluids to liberate free active drug. Al-o though this is true it does not in any way invalidate the scheme as shown in Figure 2. Protein-bound antibiotic can only give up freeis drug if the protein concentration of the fluido is relatively low which means in effect that the protein-bound fraction must be diluted. This 0 at once means that the concentrations of drug을 in question will be low but more important,any tendency to increase the level of free drug in a tissue will result immediately in diffusion ${ }_{\varnothing}$ back into the vascular system as is the casez when serum concentrations fall due to excretion.

It will be seen that levels of total drug serum, or in a tissue, are of little significanees in themselves since they give no indication to what proportion is active and freely diffus-o ible, and what proportion is bound. The sames criticism can be applied to determinations of so called "antibacterial activity in serum". These determinations are commonly carried out $\stackrel{\mathbb{D}}{\circ}$ by making two-fold dilutions of serum samples $\overrightarrow{\mathrm{O}}$ in broth. This has the effect of dissociating 3 the protein-bound fraction so that the resulting figure is an index of the total amount of anti-? biotic present without any indication of the proportions bound and free.

Antibiotic levels in serum should be con- $-\frac{5}{3}$ sidered in relation to the extent to which the drug is bound, and the resulting level of free antibiotic can then be considered in relation to the known activity of the drug. 